\title{
FDF Manufacture
}

National Cancer Institute

\section{Source}

National Cancer Institute. FDF Manufacture. NCI Thesaurus. Code C101510.

The act of making a product as ready to be utilized or consumed by the end user. 